\title{
DANÇA E CULTURAS JUVENIS NO ENSINO MÉDIO
}

\author{
Joyce Cristina Claro Menoti ${ }^{1}$, Márcia Regina Canhoto de Lima ${ }^{2}$
}

${ }^{1}$ Mestre em Educação pela Universidade Estadual Paulista (UNESP), campus de Presidente Prudente, SP. Membro do Centro de Estudos e Pesquisa em Educação, Ludicidade, Infância e Juventude - CEPELIJ. E-mail: joyce cris 1012@hotmail.com

${ }^{2}$ Doutora pelo Programa de Pós-Graduação em Educação da Universidade Estadual Paulista (UNESP), campus de Marília. Docente do Departamento de Educação Física e do Programa de Pós-Graduação em Educação da Universidade Estadual Paulista (UNESP), campus de Presidente Prudente, SP.

\section{RESUMO}

O presente artigo refere-se a um recorte da dissertação intitulada "Os jovens e as Danças nas aulas de Educação Física: um desvelar das Culturas Juvenis" desenvolvida junto ao Programa de Pós-Graduação em Educação da Faculdade de Ciências e Tecnologia, UNESP - Campus de Presidente Prudente, vinculada à Linha de Pesquisa: Processos formativos, infância e juventude. A pesquisa realizada em uma escola da rede pública de ensino decorreu da constatação de uma professora de Educação Física de que dentre todas as manifestações corporais da Educação Física escolar (esportes, atividades rítmicas/danças, jogos, lutas e ginástica), os jovens alunos do Ensino Médio participavam menos quando se tratavam das aulas com o conteúdo dança. Perante essas evidências, objetivamos compreender os motivos e as justificativas dos alunos no que se referem à vivência do conteúdo dança nas aulas de Educação Física e verificar como a dança, conteúdo da cultura corporal de movimento, era trabalhada nas aulas de Educação Física pela professora para que esta alcançasse seus objetivos. Empregamos metodologia de abordagem qualitativa com pressupostos da pesquisa do tipo etnográfica e utilizamos como procedimentos metodológicos para coleta e análise dos dados, respectivamente, o questionário, a observação participante, a entrevista semiestruturada e a triangulação dos dados. Os participantes foram os jovens alunos de uma sala de 20 ano do Ensino Médio e a professora de Educação Física dessa turma. Os resultados demonstraram que apesar das literaturas referentes aos estudos no campo da juventude, bem como da dança apontarem que a dança faz parte das manifestações culturais juvenis, na escola investigada ela não estava presente nas manifestações da cultura corporal de movimento dos jovens alunos no seu cotidiano, refletindo na recusa ou pouca participação nas aulas de Educação Física com este conteúdo. Diante disso, sublinhamos que é preciso conhecer os jovens alunos, bem como respeitar as suas manifestações culturais juvenis no âmbito escolar para que o Ensino Médio, de fato, seja significativo.

Palavras-chave: Dança. Educação Física. Ensino Médio. Culturas Juvenis. Currículo do Estado de São Paulo.

\section{DANCE AND YOUTH CULTURES IN MIDDLE SCHOOL}

\section{ABSTRACT}

This article refers to a dissertation section entitled "Young people and Dances in Physical Education classes: an unveiling of Youth Cultures" developed by the Graduate Program in Education of the Faculty of Sciences and Technology, UNESP - Campus Of Presidente Prudente, linked to the Research Line: Formative processes, childhood and youth. The research carried out in a public school system was based on the observation of a Physical Education teacher that among all physical manifestations of physical school education (sports, rhythmic activities / dances, games, fights and gymnastics), young students of the High school participated less when it came to classes with dance content. In light of these evidences, we aimed to understand students' motives and justifications regarding the experience of dance content in physical education classes and to verify how dance, the content of body movement culture, was worked on in Physical Education classes by the teacher to That it achieved its goals. We used a methodology of qualitative approach with ethnographic research assumptions and used as methodological procedures for collecting and analyzing the data, respectively, the questionnaire, the participant observation, the semistructured interview and the triangulation of the data. The participants were the young students of a room of 2nd year of High School and the teacher of Physical Education of this class. The results showed that although the literature referring to studies in the field of youth as well as dance pointed out that dance is part of the youth cultural manifestations, in the school investigated it was not present in the manifestations 
of the body movement culture of the young students in their daily life, Reflecting the refusal or little participation in the classes of Physical Education with this content. Given this, we emphasize that it is necessary to know the young students, as well as to respect their cultural manifestations of youth in the school environment so that the High School, in fact, is significant.

Keywords: Dance. Physical Education. High school. Youth Cultures. Curriculum of the State of São Paulo.

\section{INTRODUÇÃO}

O presente artigo trata-se de um recorte da dissertação intitulada "Os jovens e as Danças nas aulas de Educação Física: um desvelar das Culturas Juvenis" vinculada ao Programa de Pós-Graduação em Educação da UNESP, campus de Presidente Prudente. Surgiu a partir da constatação de uma professora do Ensino Médio de que dentre todos os conteúdos da Educação Física, os jovens alunos participavam menos ou se recusavam a participar das aulas com o conteúdo dança.

Por sua vez, as literaturas referentes aos estudos no campo da Sociologia da Juventude nos explicitavam que a dança faz parte dos ambientes de convívio dos jovens e que esta cultura corporal está presente nas manifestações culturais juvenis.

Diante desta constatação, fizemos uma busca em trabalhos de teses e dissertações, que abordavam o tema das culturas juvenis e da dança na escola. Selecionamos três bases de dados principais: banco de teses e dissertações da Coordenadoria de Aperfeiçoamento de Pessoal de Nível Superior - CAPES, a Cáthedra biblioteca digital de teses e dissertações da Universidade Estadual Paulista - UNESP e na biblioteca digital da Universidade de São Paulo USP.

Os resultados dessa busca nos demonstraram que ainda é recente o crescimento de pesquisa no âmbito educacional sobre culturas juvenis conforme aponta Spósito (2009), sendo em sua maioria realizadas no âmbito da psicologia. Quando encontrado alguma relação entre culturas juvenis e a dança na área da educação, todos se referiam à situações fora do ambiente escolar.

Neste sentido, destacamos como problema dessa investigação: porque os jovens alunos na escola, especificamente, nas aulas de Educação Física participam menos das aulas de dança se a mesma faz parte das manifestações culturais juvenis, sendo vivenciada pela maioria dos jovens alunos em diversos contextos?
A partir desse problema surgiram alguns questionamentos sobre como a dança estava presente nas aulas de Educação Física, sobre como os jovens alunos se manifestavam (ou não) pela dança dentro e fora da escola, como a professora de Educação Física se relacionava com os jovens e como era sua vivência em relação à dança.

Frente a esses questionamentos, definimos como objetivo geral da pesquisa: analisar as relações dos jovens alunos com a dança nas aulas de Educação Física, visando compreender o nível de participação nas práticas educativas relacionadas a este conteúdo. Para isso, estabelecemos como objetivos específicos: compreender os motivos e as justificativas de não participação dos alunos no que se referem à vivência do conteúdo dança nas aulas de Educação Física e verificar como a dança, conteúdo da cultura corporal de movimento, era trabalhada nas aulas de Educação Física pelo professor e qual a importância dela para que este alcançasse seus objetivos.

\section{METODOLOGIA}

Marconi e Lakatos (2005, p.83), definem o método como "o conjunto de atividades sistemáticas e racionais que, com maior segurança e economia, permite alcançar o objetivo - conhecimentos válidos e verdadeiros -, traçando o caminho a ser seguido [...]". Desse modo, ele é embasado sempre por conceitos científicos, filosóficos, políticos e sociais do pesquisador, consequentemente, a escolha pelo método é feita a partir do seu objeto de pesquisa, uma vez que ele definirá qual método científico deverá ser utilizado.

A partir disso, nossa pesquisa assumiu a abordagem qualitativa, visto que teve ambiente natural como fonte de dados e o pesquisador como seu principal instrumento (LÜDKE; ANDRÉ, 1886).

Nesse sentido, para Prodanov e Freitas $(2013$, p.70) 
[...] $\mathrm{Na}$ abordagem qualitativa, a pesquisa tem o ambiente como fonte direta dos dados. 0 pesquisador mantém contato direto com o ambiente e o objeto de estudo em questão, necessitando de um trabalho mais intensivo de campo. Nesse caso, as questões são estudadas no ambiente em que elas se apresentam sem qualquer manipulação intencional do pesquisador.

Como método de procedimento, adotamos a pesquisa do tipo etnográfico por compreender, segundo André (2005, p.24), que a etnografia foi desenvolvida por antropólogos para "descrição cultural" em dois sentidos: "[...] (1) um conjunto de técnicas que eles usam para coletar dados sobre os valores, os hábitos, as crenças, as práticas e os comportamentos de um grupo social; e (2) um relato escrito resultante do emprego dessas técnicas". Entretanto, esse tipo de pesquisa no campo educacional tem como preocupação central o processo educativo, o que possibilita aos pesquisadores da área abrir mão de certos requisitos da etnografia (ANDRÉ, 2005).

Após determinação dos métodos, a presente pesquisa foi enviada para o Comitê de Ética em Pesquisa (CEP) da Faculdade de Ciências e Tecnologia - UNESP, câmpus de Presidente Prudente através da Plataforma Brasil, sendo devidamente analisada e aprovada por meio do parecer consubstanciado número 1.515.176.

Para coleta de dados utilizamos como instrumentos: o questionário fechado, as observações participantes nas aulas de Educação Física, anotações no diário de campo e a entrevista semiestruturada com roteiro préestabelecido, gravada em áudio.

Os dados foram coletados no período de um ano e meio letivo, os quais tiveram a coleta iniciada no segundo semestre do ano de 2015 e finalizada no fim do segundo semestre do ano de 2016. Desse modo, a pesquisadora acompanhou os alunos no 2 ㅇ e 3 ㅇ anos do Ensino Médio.

Os sujeitos que compuseram a pesquisa foram os jovens alunos de uma sala do 2 - ano do Ensino Médio de uma escola da rede estadual pública de uma cidade de médio porte, localizada no interior do estado de São Paulo. A escolha desta unidade escolar, em particular, ocorreu de forma intencional, haja vista que a professora de Educação Física da instituição constatou que dentre todos os eixos de conteúdos da Educação Física (esportes, atividades rítmicas/dança, jogos, ginásticas e lutas) os jovens alunos participam menos quando o conteúdo se referia à dança. Diante disso, foi aplicado o "questionário 1" (sem a identificação dos alunos) para as cinco salas de 2ㅇ ano do Ensino Médio da escola, a fim de diagnosticar em qual delas a maioria dos alunos declaravam não gostar de participar das aulas de dança, o qual identificou essa turma sendo o 2 ㅇ A.

Posteriormente, aplicamos $\mathrm{O}$ "questionário 2" para todos os alunos do $20 \mathrm{~A}$, a fim de identificar além da participação (ou não) nas aulas de Educação Física, a presença da dança no contexto juvenil fora dos ambientes escolares, nos seus locais informais de convívio.

Aliada as respostas dos questionários realizamos as observações participantes e percebemos que havia algumas divergências entre o que foi dito e as atitudes de alguns jovens. Por exemplo, alguns diziam não gostar de dançar, entretanto participaram de todas as atividades de dança e vice-versa. A partir disso, entendemos ser necessário confrontar essas afirmações/atitudes por meio de entrevista semiestruturada. Nesse processo, também entrevistamos a professora da turma com o objetivo de compreender as suas principais vivências e dificuldades em relação ao conteúdo dança.

Para a análise dos dados, a fim de alcançar a máxima amplitude na descrição, explicação e compreensão do objeto pesquisado utilizamos a triangulação de dados (TRIVIÑOS, 1987), que segundo Minayo (2012, p.622) explica toda pesquisa qualitativa é composta pelos termos estruturantes, "[...] experiência, vivência, senso comum e ação [...]" que exigem a compreensão, a interpretação e a dialética para sua análise.

\section{RESULTADOS}

Ao investigar o perfil dos jovens alunos, constatamos que dos 34 alunos que responderam o questionário, 8,82\% (3) tinha idade de 15 anos; $73,52 \%$ (25) idade de 16 anos; $14,70 \%$ (5) tinha 17 anos e 1 dos alunos tinha 19 anos totalizando $2,94 \%$. Considerando a data de aplicação do questionário (mês fevereiro) entendemos que de 
acordo com as legislações do Ensino Médio, os alunos encontravam-se na "idade certa" de escolarização.

Obtivemos também que os jovens alunos ainda cursando o Ensino Médio já exerciam atividades remuneradas, nas quais a maioria trabalhava somente à tarde ou em horários aleatórios. Podemos observar no gráfico
1, que foi significativo o número de alunos que exerciam atividades remuneradas, dentre eles, 2 não responderam $(5,88 \%), 5$ faziam bicos $(14,70 \%), 1$ recebia mesada e fazia bicos $(2,94 \%)$, 6 trabalhavam $(17,64 \%), 3$ faziam estágio $(8,82 \%), 4$ ganhavam mesada $(11,76 \%)$ e 14 não tinham nenhuma fonte de renda $(41,17) \%$.

Gráfico 1. Você exerce alguma atividade remunerada?

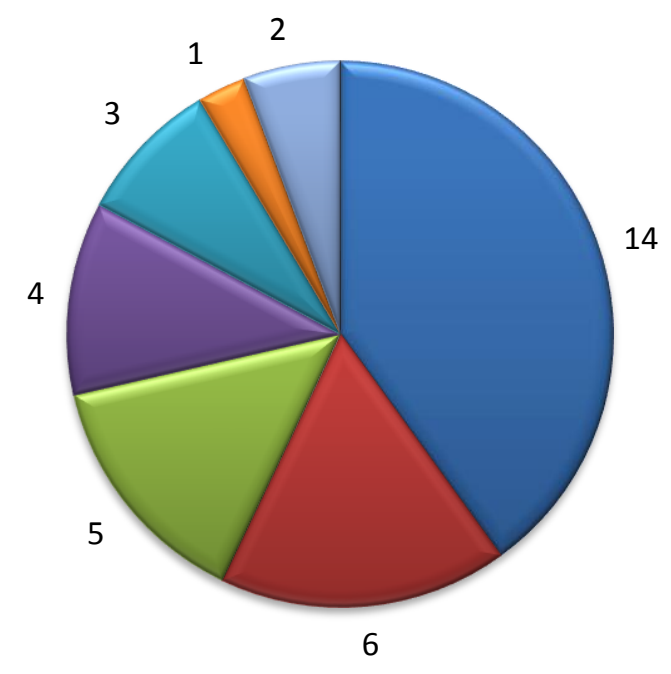

15 Nenhuma

घ6 Trabalho

$\square 4$ Bicos

$\square 4$ Mesada

$\square 3$ Estágio

Mesada e Bicos

$\square$ N.R

Fonte: $\mathrm{O}$ autor.

Verificamos de modo geral, que a maioria tinha idade de 16 anos, se considerava branca, tinha renda mensal familiar entre $\mathrm{R} \$ 1.000,00$ e $\mathrm{R} \$ 2.000,00$, bem como uma porcentagem significativa exercia atividades extra escolares remuneradas.

Quando perguntados, no gráfico 2, sobre o que mais gostavam de fazer no tempo livre, dentre as opções disponibilizadas, as quais poderiam ser assinaladas mais de uma alternativa, as atividades preferidas foram: 29 ficar na internet, 20 assistir tv, 14 jogar vídeo game, 13 sair com amigos ou namorado(a), 11 gostavam de não fazer nada, 8 ir à festas ou balada, 7 praticar esportes ou fazer atividades físicas, 7 dançar e 5 estudar.

Gráfico 2. O que você mais gosta de fazer em seu tempo livre?

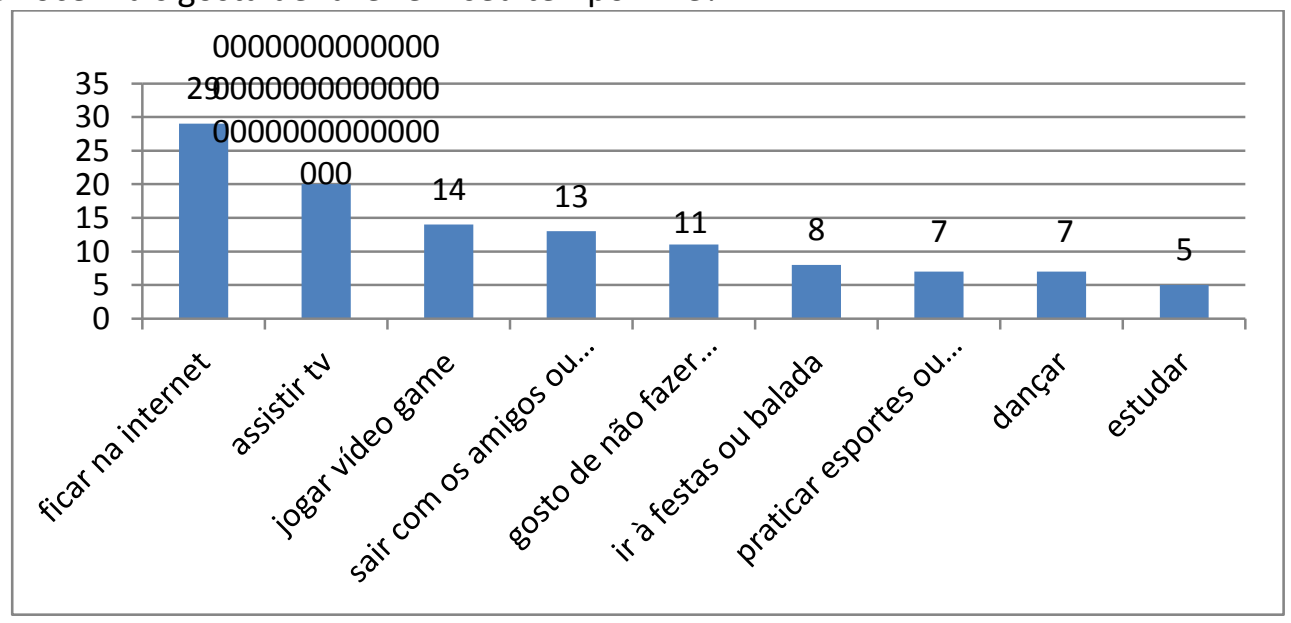

Fonte: $\mathrm{O}$ autor. 
Posteriormente, iniciamos as questões que se referiam à dança dentro e fora do contexto escolar. Ao perguntarmos se gostavam de dançar fora da escola, $21(61,76 \%)$ alunos responderam que não e 13 (38,23\%) responderam que sim. Na mesma proporção, quando perguntados se gostavam de participar das aulas de dança na Educação Física, a maioria dos alunos respondeu que não, totalizando 21 $(61,76 \%)$ respostas e $10(29,41 \%)$ responderam que sim, ficando $3(8,82 \%)$ alunos sem responder.

A professora de Educação Física da turma, por sua vez, destacou na entrevista que tinha uma dificuldade particular com a dança por não ser uma manifestação cultural presente em sua vida e por ter sido um conteúdo deficiente em sua formação inicial. Apesar dessas dificuldades, explicitou que buscava formas diferenciadas para trabalhar o conteúdo, na tentativa de apresentá-lo com qualidade, aliando recursos audiovisuais às atividades propostas pelo currículo oficial do Estado de São Paulo.

Os jovens alunos que alegaram não gostar de dança na escola elencaram diversos motivos como justificativa, que podem ser verificadas no quadro 1.

Quadro 1. Se não, porque não gosta de dançar nas aulas de Educação Física?

\begin{tabular}{|l|l|}
\hline \multicolumn{1}{|c|}{ Vergonha } & \multicolumn{1}{|c|}{ Não gosta de dança } \\
\hline $\begin{array}{l}\text { Além da vergonha, há uma porção de gente } \\
\text { vendo, e eu não gosto }\end{array}$ & (5) Não gosto de dançar \\
\hline $\begin{array}{l}\text { Na frente de todos não dá, pois a vergonha toma } \\
\text { conta }\end{array}$ & $\begin{array}{l}\text { Não gosto de dançar: "É uma coisa que não me } \\
\text { faz sentir bem" }\end{array}$ \\
\hline Porque a vergonha toma conta! & Exatamente porque eu não gosto de dançar \\
\hline Não tenho vontade e tenho vergonha & Porque odeio dançar e tirar fotos \\
\hline $\begin{array}{l}\text { Porque tenho muita vergonha e não sei dançar } \\
\text { nada }\end{array}$ & \multicolumn{1}{|c|}{ Outros } \\
\hline Porque não gosto de dançar em público & $\begin{array}{l}\text { Não sou muito bom com dança } \\
\text { Não me sinto á vontade }\end{array}$ \\
\hline $\begin{array}{l}\text { Ps danças não são tão legais quanto os outros } \\
\text { esportes }\end{array}$ & É chato \\
\hline Prefiro praticar esportes & $\mathbf{2}$ Não responderam \\
\hline
\end{tabular}

Fonte: $\mathrm{O}$ autor.

Os resultados provindos dos questionários, entrevistas e observação participante demonstraram que os jovens alunos participavam com menos frequência das aulas de Educação Física com o conteúdo dança por dois principais motivos: porque esta manifestação não fazia parte das manifestações culturais juvenis da maioria dos jovens alunos fora do ambiente escolar e por sentirem vergonha durante as aulas na escola.

\section{DISCUSSÕES}

Sobre o perfil dos jovens alunos, em relação a sua média de idade, suscitamos a discussão sobre a categorização de juventude por idade. De acordo com a atual legislação brasileira, considera-se jovem uma pessoa entre a faixa etária de 15 a 29 anos, embora até os 18 anos, aplica-se a definição do Estatuto da Criança e do Adolescente - ECA.
Todas as políticas públicas estudantis ou não, são orientadas por essa definição pautada em aspectos apenas naturalistas e biologicistas. $\mathrm{Na}$ contracorrente, autores que tratam do tema da juventude, em sua maioria sociólogos, defendem uma revisão da definição de juventude, uma vez que ela é uma categoria conceitualmente imprecisa numericamente (SPÓSITO, 1997).

Para discutir o que vem a ser juventude, antes de tudo, é necessário compreender que ela, além de fruto biológico e psicológico é, também, uma construção social que varia de acordo com as diferentes culturas e no interior de cada cultura (CATANI, GILIOLI, 2008). Essa visão está muito presente na escola negando o presente em nome de projetos futuros que o jovem poderá concretizar, uma vez que no presente ele é apenas um "vir a ser" e a juventude é encarada como uma fase de 
passagem (entre a infância e a vida adulta) (DAYRELL, 2003).

Jhonatan: Não tenho 18,
então pela lei me
considero adolescente.
Mas se for por
consideração minha eu me
identificaria como um
jovem adulto, eu acho. Eu
levo em consideração o
meu tempo de vida. Não a
parte burocrática de ter 18
pela lei e tal. Mas pelo
meu tempo de vida,
acredito. Só vou falar que
sou finalmente adulto,
acho que com uns 25 anos.

Dayrell (2003) expõe que conceituar juventude é uma tarefa muito difícil porque ela abarca conceituações históricas, culturais e varia de acordo com cada sociedade, tempo histórico e sociedades que os representam. Desse modo, se faz necessário pensar em juventude diante das diversidades que a cercam ao invés de delimitálas, mas, é preciso também, considerar seus aspectos singulares.

Em relação às outras características do perfil dos jovens alunos como a etnia, a renda familiar e as atividades remuneradas, Krawczyk (2014) aponta que mais de que qualquer outro nível de ensino, as transformações de ordem social, econômica e cultural afetaram a educação pública em diversos países, principalmente no Ensino Médio.

Quando tratamos sobre o que jovens alunos gostam de fazer fora da escola, diversas manifestações culturais foram elencadas e, nesse sentido, Filipouski e Nunes (2012), salientam que, por meio das manifestações artísticas e culturais, os jovens invertem a lógica que costuma reduzir a juventude a uma etapa de riscos para se situarem em seu tempo, ampliar os horizontes e construir projetos de vida.

Diante desse cenário, os jovens ocupam os espaços urbanos na tentativa de reconquistar de modo alternativo, uma vez que a juventude é um produto da cidade, particularmente afetado pelos problemas e vantagens dos espaços urbanos (CATANI; GILIOLI, 2008).

Por fim, ao questionarmos se os jovens alunos gostavam de dançar dentro e fora do contexto escolar, analisamos que em igual escala eles não gostam de dançar, desse modo, esses dados justificaram a realização da pesquisa, visto que foram contra a corrente de que o Brasil é um país dançante conforme apontam Marques (2003) e o currículo do Estado de São Paulo (2010), que dentre as manifestações culturais juvenis a dança está presente de modo expressivo.

Eles também elucidaram a necessidade de lançar um olhar para as culturas juvenis nas unidades escolares, vislumbrar as expectativas juvenis fora dos ambientes estudantis para que elas também possam ser consideradas dentro da escola e, assim, estabelecer o diálogo entre a necessidade do jovem aluno e as metas educacionais.

Embora tenham contabilizado menos de $40 \%$ dos que demonstraram gostar de dança, quando perguntamos onde os jovens alunos gostam de dançar, eles apontaram como locais preferidos os ambientes em que, geralmente, a família não está presente (festa entre amigos, sozinho no quarto, show, balada) ou locais em que os familiares, mesmo presente, possam se afastar (aniversário, festa em família, formatura).

Moreno et. al. (2006) explicam que o sentimento de vergonha na cultura escolar, tratase de a vergonha ser o lugar do juízo alheio, visto que ela tem motivações afetivo-emocionais e racionais. Além disso, muitas vezes, tem a ver apenas com a exposição do corpo, sem necessariamente, sofrer algum juízo de valor. Nesse sentido, compreendemos que a Educação Física é a disciplina escolar que mais propõe atividades de exposição corporal e, dessa forma, é natural que a vergonha seja um elemento que contribui para a recusa de participação nas aulas, mesmo que os alunos revelem que dançam em outros contextos.

\section{CONSIDERAÇÕES FINAIS}

Apesar das políticas públicas destinadas aos alunos do Ensino Médio terem sofrido aumento nas duas últimas décadas, a juventude ainda é encarada com caráter de transitoriedade entre a infância e a fase adulta, estabelecida biologicamente pela idade, na qual, o estado atual manifesta um "vir a ser" de alguém que no momento, apresenta problemáticas. Apresentouse, então, duas maneiras distintas de conceito de juventude na sociedade: a de jovem problemático ligado a irresponsabilidade e à problemas sociais e ao jovem como potente consumidor.

Um descompasso foi criado a partir desses impasses e dentre a já existente crise 
educacional, agravou-se a incomunicabilidade entre os agentes escolares. Os jovens alunos sentem-se pressionados num ambiente de extrema cobrança, no qual, suas perspectivas não são incorporadas e por isso, a escola não tem significado e perde o sentido para eles. Ao mesmo tempo, nos seus espaços-tempos informais de convívio, os jovens alunos podem se manifestar por meio das culturas juvenis que exprimem, no mesmo ritmo, suas igualdades e peculiaridades.

Dentre essas manifestações, a dança aparece de modo significativo de acordo com os autores abordados. Diante disso, ela pode ser um agente que possibilite a incorporação dessas manifestações culturais juvenis dentro da escola, nas aulas de Educação Física. Entretanto, constatamos que embora da dança faça parte das culturas juvenis, esse fato não determina que em todas as culturas juvenis ela tenha sentido.

$\mathrm{Na}$ escola investigada os alunos demonstraram que nem todos apreciam ou gostam de dançar, independentemente, se dentro ou fora do contexto escolar, ou seja, não é garantia de que um mesmo elemento que faça parte das culturas juvenis, por exemplo, a dança em uma cidade metropolitana, também compõe as culturas juvenis em uma cidade do interior. Além disso, o trabalho docente do professor interfere no significado que esse conteúdo poderá ter.

O currículo do Estado de São Paulo incorpora a dança como um dos conteúdos da Educação Física e apresenta situações de aprendizagem com descrição de atividades nos cadernos do professor e do aluno. A professora por sua vez, realiza as atividades em sala de aula e propõe um trabalho coletivo da construção de uma coreografia pelos jovens alunos. Eles expõem que a coreografia, muitas vezes, limita suas manifestações além do HIP HOP não fazer parte das suas manifestações culturais.

Nesse sentido, a professora ao seguir o currículo sublinha a sua ineficiência nas escolas, uma vez que quando aponta atividades com caráter obrigatório o professor fica limitado a elas, não podendo partir dos conhecimentos que os alunos trazem.

Aliado a isso, os jovens apresentaram como motivações para não participar das aulas de Educação Física com o conteúdo dança a vergonha que sentem quando, no âmbito escolar, se expressam corporalmente na frente dos outros alunos. Para isso, sugerem atividades com estilos que permitam a dança em dupla, porém, o currículo é inflexível.

Diante do exposto, ressaltamos que não desejamos encerrar as discussões sobre a temática, pelo contrário, pretendemos que os esforços aqui empreendidos possam contribuir com os debates e discussões realizadas nas áreas de Juventude, Educação Física escola, Dança e currículo do Estado de São Paulo.

\section{REFERÊNCIAS}

ANDRÉ, Marli Eliza Dalmazo Afonso de. Etnografia da prática escolar. São Paulo: Papirus, 2005.

CATANI, Afrânio Mendes; GILIOLI, Renato de Sousa Porto. Culturas juvenis: múltiplos olhares. (Paradidáticos. Série Cultura). São Paulo: Editora UNESP, 2008. 113p.

DAYRELL, Juarez Tarcisio. O jovem como sujeito social. Revista Brasileira de Educação, n.24, p.4052, set./dez. 2003.

KRAWCZYK, Nora. A encruzilhada da instituição escolar In: KRAWCZYK, Nora (org.). Sociologia do Ensino Médio: crítica ao economicismo na política educacional. São Paulo: Cortez, 2014. p. 7-12.

LÜDKE, Menga; ANDRÉ, Marli Eliza Dalmazo Afonso. Pesquisa em educação: abordagens qualitativas. São Paulo: Pedagógica e Universitária, 1986.

MARCONI, Marina de Andrade; LAKATOS, Eva Maria. Fundamentos de Metodologia Científica. 6. ed. São Paulo: Atlas, 2005.

MARQUES, Isabel Azevedo. Dançando na escola. São Paulo: Cortez, 2003. p. 19-32.

MINAYO, Maria Cecília de Souza. Análise qualitativa: teoria, passos e fidedignidade. Ciência \& Saúde Coletiva, Rio de Janeiro, v.17, n. 3, p. 621-626, mar. 2012. Disponível em: https://doi.org/10.1590/S1413-

81232012000300007. Acesso em: 10 jan. 2016.

MORENO, Bruno Stramandinoli; POLATO, André Luís; MACHADO, Afonso Antonio. Aluno e seu corpo nas aulas de educação física: apontamentos para uma reflexão sobre a vergonha e a mídia. Movimento \& Percepção, 
Espírito Santo de Pinhal, SP, v.6, n.8, jan./jun. 2006.

PRODANOV, Cleber Cristiano; FREITAS, Ernani Cesar de. Metodologia do trabalho científico [recurso eletrônico]: métodos e técnicas da pesquisa e do trabalho acadêmico. 2. ed. Novo Hamburgo: Feevale, 2013.

SÃO PAULO (Estado). Secretaria da Educação. Currículo do Estado de São Paulo: Linguagens, códigos e suas tecnologias. São Paulo: SEE, 2010. $216 \mathrm{p}$.

SPÓSITO, Marília Pontes. Estudos sobre juventude em educação. Revista Brasileira de Educação, Rio de Janeiro, n.5, p-37-52 mai./ago. 1997.

SPÓSITO, Marília Pontes. A pesquisa sobre Jovens na Pós-Graduação: um balanço da produção discente em Educação, Serviço Social e Ciências Sociais (1999-2006); In: SPÓSITO, Marília Pontes (Coord.). O Estado da arte sobre a juventude na pós-graduação brasileira: educação, ciências sociais e serviço social (1999- 2006). Belo Horizonte: Argvmentvm, 2009. p. 57-126.

TRIVIÑOS, Augusto Nibaldo Silva. Introdução à pesquisa em ciências sociais: a pesquisa qualitativa em educação. São Paulo: Atlas, 1987.

Recebido para publicação em: 16/08/2017

Revisado em: 18/09/2017

Aceito em: 27/09/2017 